\title{
Anesthesia for Ex Utero Intrapartum Treatment (EXIT procedure) in Fetus with Prenatal Diagnosis of Oral and Cervical Malformations: Case Reports
}

\author{
Daniel Corrêa Helfer ${ }^{1}$, Jefferson Clivatti ${ }^{2}$, Américo Massafuni Yamashita, TSA ${ }^{3}$, Antonio Fernades Moron ${ }^{4}$
}

\begin{abstract}
Helfer DC, Clivatti J, Yamashita AM, Moron AF - Anesthesia for Ex Utero Intrapartum Treatment (EXIT procedure) in Fetus with Prenatal Diagnosis of Oral and Cervical Malformations: Case Reports.

Background and objectives: Fetus prenatally diagnosed with neck tumors, or with any other disease that obstructs the airways, should not be treated conventionally, as the assistant physician has to face two challenges right after the infant's delivery: the limited time to establish the access to the potentially difficult airways and the lack of anesthesia of the neonate in case of instrumentation of the airways. The ex utero intrapartum treatment, i.e., the EXIT procedure consists of maintaining the fetoplacental circulation during the cesarean section, until the airways of the fetus be secured.

Case Reports: Female patient, 37 years old, G3P2, 38 weeks pregnant, having polyhydramnios and fetus diagnosed with large cervical masses by prenatal ultrasound. A cesarean section was performed using the EXIT procedure to enable safe access to the infant's airways. After hysterotomy, the fetus was intubated by direct laryngoscopy. The neonate was immediately transferred to another operating room, where cervical tumor resection of the neck tumor and tracheostomy were successfully performed. Female patient, 27 years old, G3P1A1, 32 weeks pregnant, whose fetus was prenatally diagnosed with a large oral tumor. As the tumor obstructed the fetus' airways, a tracheostomy was performed when the fetus underwent EXIT procedure. It was then possible to use direct laryngoscopy for neonate intubation. The fetus underwent tumor resection and was sent to the Neonatal Intensive Care Unit.
\end{abstract}

Conclusions: Reports describe the successful use of general anesthesia with isoflurane for cesarean delivery followed by the EXIT procedure in fetus diagnosed with tumors obstructing the airways.

Keywords: Cesarean Section; Congenital, Hereditary, and Neonatal Diseases and Abnormalities; Fetal Therapies; Isoflurane; Prenatal Diagnosis.

\section{INTRODUCTION}

Fetuses with large cervical or oral tumors obstructing the airways, who are delivered via cesarean section, are associated to high mortality rates following delivery due to difficulties related to ventilation, intubation and tracheostomy ${ }^{1}$.

Recent advances in image diagnosis have enabled early detection of tumors obstructing fetuses' airways, makimg possible to plan strategies of accessing these airways before delivery ${ }^{2,3}$.

Received from the Universidade Federal de São Paulo, Escola Paulistade Medicina, Brazil.

1. Physician in Specialization; Resident of the Department of Anesthesiology, Pain and Intensive Care, Universidade Federal de São Paulo - Escola Paulista de Medicina (Unifesp-EPM)

2. Anesthesiologist; Anesthesiology Physician, Unifesp-EPM

3. Assistant Professor, Department of Anesthesiology, Pain and Intensive Care, Unifesp-

EPM

4. PhD; Full Professor, Discipline of Obstetrics, Unifesp-EPM

Submitted on April 27, 2011.

Approved on August 3, 2011.

Correspondence to:

Daniel Corrêa Helfer, MD

Rua Napoleão de Barros, 715, $4^{\circ}$ Andar

Vila Clementino

04024002 - São Paulo, SP, Brazil

Email: helferdc@yahoo.com.br
The EXIT procedure (ex utero intrapartum treatment) consists in maintaining the fetoplacental circulation during the cesarean section until the neonate's airways be secured ${ }^{1,4-7}$. It is a procedure used in situations in which the fetus has obstructed airways at the end of pregnancy. The anesthetic technique used for this procedure must offer maternal anesthesia, appropriate uterine relaxation, fetal anesthesia and fetal immobility during his manipulation ${ }^{2,8-10}$.

This paper reports two successful cases of EXIT procedure performed in fetuses prenatally diagnosed with airway obstruction, and it discusses the techniques used through a short literature review.

\section{CASE REPORTS}

Before procedure, the patients and their family were informed of the surgical and anesthetic techniques.

\section{Case 1}

Female patient, 37 years old, G3P2, 38 weeks pregnant, ASA I, having polyhydramnios and fetus diagnosed with large cervical masses by prenatal ultrasound. A cesarean section 
was performed using the EXIT procedure to enable safe access to the infant's airways while maintaining the fetoplacental circulation. The programmed anesthetic technique was the balanced anesthesia with fentanyl and isoflurane. During the preoperative period, intravenous metoclopramide (10 mg) and ranitidine $(50 \mathrm{mg}$ ) were administered. The mother was monitored by pulse oximeters, heart rate monitors, noninvasive blood pressure monitors, capnography, anesthetic gas analyzers, and control of diuresis. The patient was positioned in a horizontal dorsal position, with arms open. The uterus was moved to the left with a "crawford wedge". After having used oxygen face mask for five minutes (100\% oxygen), rapid sequence induction with fentanyl $(250 \mu \mathrm{g})$, propofol (150 mg) and succinylcholine (50 $\mathrm{mg}$ ) was performed, as well as Sellick maneuver and tracheal intubation. For anesthesia mainte- nance, it was necessary to administer $2 \%$ isoflurane with expired fraction of $1.4 \%$ in $100 \%$ oxygen, fentanyl $(100 \mu \mathrm{g})$ and atracurium $(30 \mathrm{mg})$ for muscle relaxation. There was a five minute gap between anesthesia induction and hysterotomy.

After hysterotomy, the fetus' head, body and upper extremities were delivered, and the uterine volume and the fetoplacental circulation were preserved (Figure 1). During the procedure, uterine relaxation due to $2 \%$ isoflurane was satisfactory and it was, therefore, not necessary to use additional tocolytic agents. Fetal monitoring consisted in manually controlling the umbilical cord, as well as in visual inspection (Figure 2). Eight minutes after hysterotomy, the fetus was intubated by direct laryngoscopy with a $3.0 \mathrm{~mm}$ tube without cuff (Figure 3). After assuring the right position of the tracheal tube, the umbilical cord was clamped and the fetus was delivered.

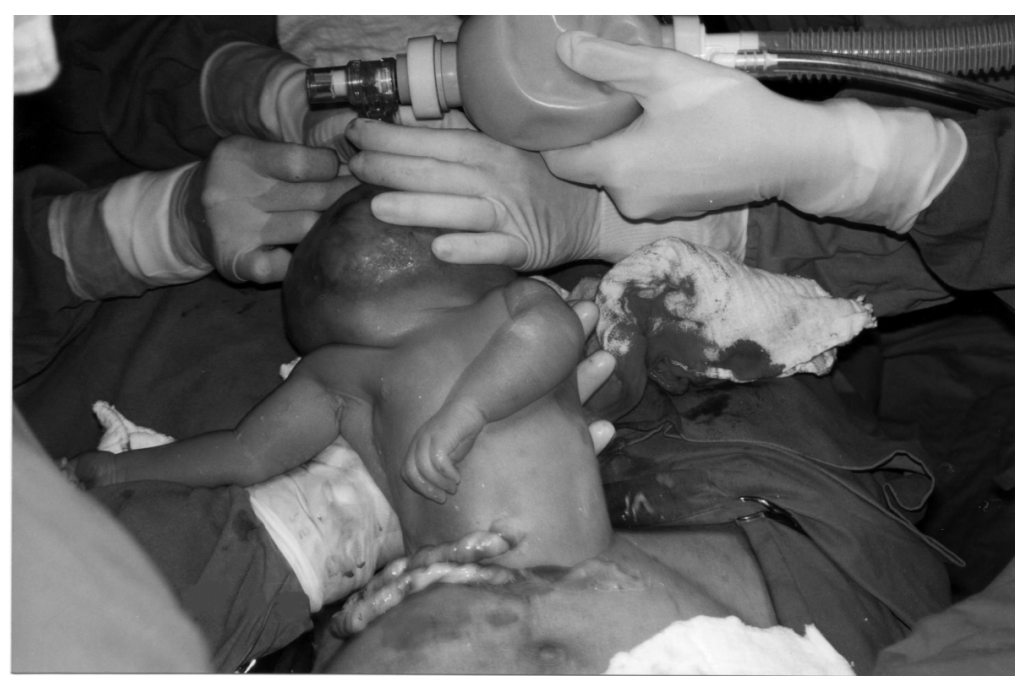

Figure 1 - Delivery of the Head, Body, Upper Extremities and of part of the Fetus' Abdomen to Approach the Airways with Complete Fetoplacetal Circulation.

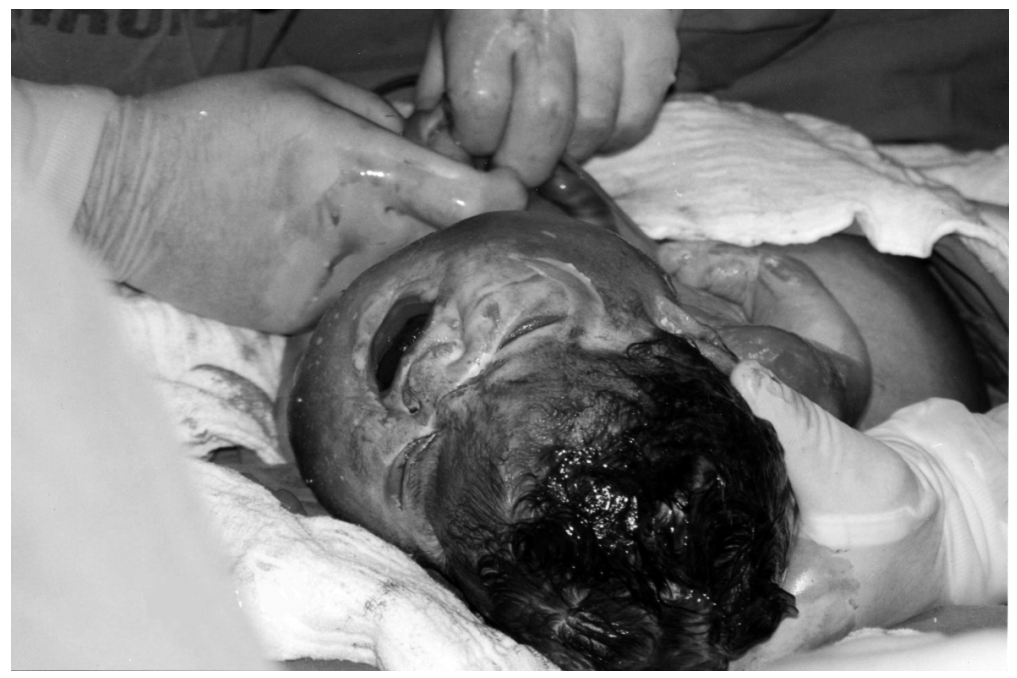

Figure 2 - Neonate with Great Cervical Tumor, and Manual Control of Umbilical Cord Beat. 


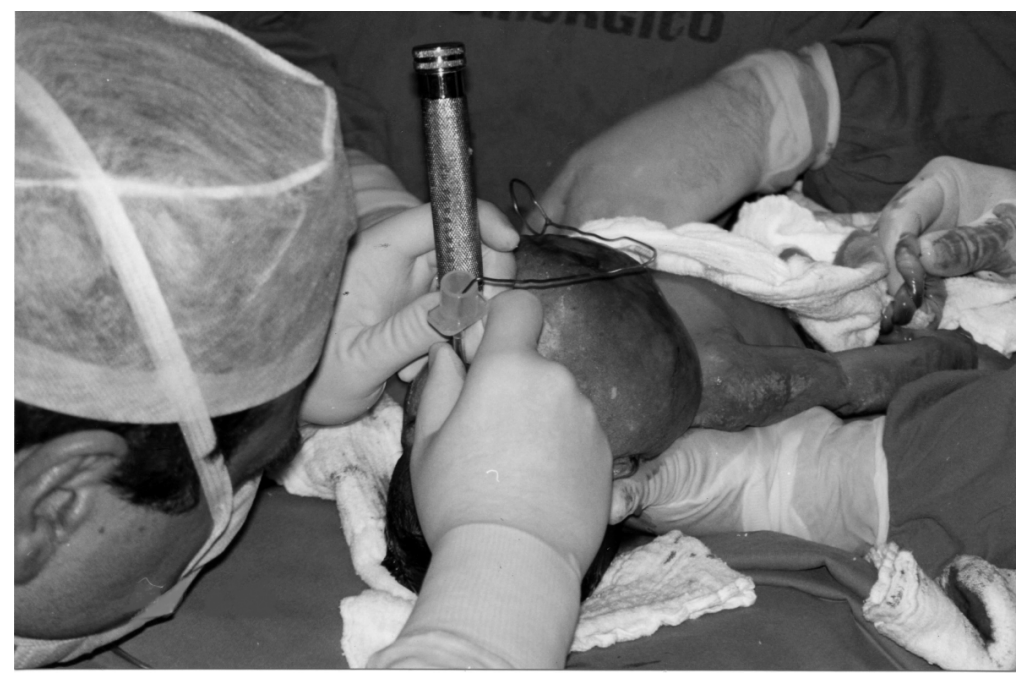

Figure 3 - Access to the Airways via Direct Laryngoscopy. Nasofiberscope Should be Available to Access the Airways in Case the Direct Laryngoscopy Does not Work.

In the first minute after the delivery of the fetus' upper extremity, the umbilical cord blood gas analysis of the arterial sample obtained was $\mathrm{pH} 7.27 ; \mathrm{pCO}_{2} 49.9 \mathrm{~mm} \mathrm{Hg}$; $\mathrm{pO}_{2} 26.5 \mathrm{~mm} \mathrm{Hg}$; and $\mathrm{SatO}_{2} 40.1 \%$. After seven minutes, the sample obtained was $\mathrm{pH} 7.24 ; \mathrm{pCO}_{2} 52.6 \mathrm{~mm} \mathrm{Hg} ; \mathrm{pO}_{2}$ $25.2 \mathrm{~mm} \mathrm{Hg}$; and $\mathrm{SatO}_{2} 35.4 \%$.

After umbilical cord clamping, constant infusion of $15 \mathrm{IU}$ oxytocin were administered to the mother, and the inspired concentration of isoflurane was reduced to $0.5 \% . \mathrm{N}_{2} \mathrm{O}$ was introduced at $50 \%$. The uterine contraction was appropriate in this procedure. The systolic blood pressure was maintained above $100 \mathrm{~mm} \mathrm{Hg}$ during the whole procedure and it was not necessary to use vasoconstrictor agents. The exhaled $\mathrm{CO}_{2}$ varied from 32 to $34 \mathrm{~mm} \mathrm{Hg}$. The total volume infused was $1,500 \mathrm{~mL}$ of crystalloids. Blood loss was estimated to be $600 \mathrm{~mL}$, and blood transfusion was not necessary. The patient was extubated at the end of the procedure without having to reverse the neuromuscular blockade.

The neonate (NN) underwent surgical resection of a cervical tumor in a previously prepared room, and the histological diagnosis was cystic hygroma.

\section{Case 2}

Female patient, 27 years old, G3P1A1, 32 weeks pregnant, ASA I, whose fetus was prenatally diagnosed with a large oral tumor. The nuclear magnetic resonance (NMR) showed a tumor suggestive of teratoma. As the tumor obstructed the fetus' airways, tracheostomy was performed when the fetus underwent EXIT procedure. Physicians used the general balanced anesthesia. The mother was monitored by pulse oximeters, heart rate monitors, noninvasive blood pressure monitors, capnography, anesthetic gas analyzers, and control of diuresis. The venous access was performed with an $18 \mathrm{G}$ catheter. After spinal anesthesia, with administration of
$100 \mu \mathrm{g}$ morphine for analgesia in the postoperative period, the patient was positioned in a dorsal position with a crawford wedge for uterus movement to the left. She was provided with $100 \%$ oxygen delivered via mask for five minutes. Rapid sequence induction of anesthesia with fentanyl $(150 \mu \mathrm{g})$, propofol $(150 \mathrm{mg})$ and succinylcholine $(100 \mathrm{mg})$ was performed. Tracheal intubation was performed with Sellick maneuver, after muscle relaxation. Anesthesia was maintained by using $2.5 \%$ isoflurane, oxygen at $100 \%$, and additional dose of fentanyl $(200 \mu \mathrm{g})$ and atracurium $(25 \mathrm{mg})$ for muscle relaxation.

Hysterotomy occurred 13 minutes after the anesthesia induction and in this case the fetus was totally delivered, but he had his uterine placental circulation preserved. During the procedure, uterine relaxation was satisfactory and it was, therefore, not necessary to use additional tocolytic agents. Fetal monitoring consisted in manually controlling the umbilical cord, as well as in visual inspection. Unlike what was previously supposed, physicians noticed the possibility of intubating the neonate's trachea. Seven minutes after hysterotomy, the fetus was intubated by direct laryngoscopy with a $3.0 \mathrm{~mm}$ tube without cuff (Figure 4). After assuring the right position of the tracheal tube, the umbilical cord was clamped (Figure 5). In a previously prepared room, the NN underwent surgical tumor resection. The surgery lasted 30 minutes approximately. The histological diagnosis was teratoma. At the end of the procedure, the neonate was sent to a neonatal ICU.

After umbilical cord clamping, constant infusion of $15 \mathrm{IU}$ oxytocin were administered to the mother, and the inspired concentration of isoflurane was reduced to $0.5 \% . \mathrm{N}_{2} \mathrm{O}$ was introduced at $50 \%$. The uterine contraction was appropriate in this procedure. The systolic blood pressure was maintained above $100 \mathrm{~mm} \mathrm{Hg}$ during the whole procedure and it was not necessary to use vasoconstrictor agents. The exhaled $\mathrm{CO}_{2}$ varied from 32 to $34 \mathrm{~mm} \mathrm{Hg}$. The total volume infused was $2,000 \mathrm{~mL}$ of crystalloids. Blood loss was estimated to be $1,100 \mathrm{~mL}$, and blood transfusion was not necessary. The 


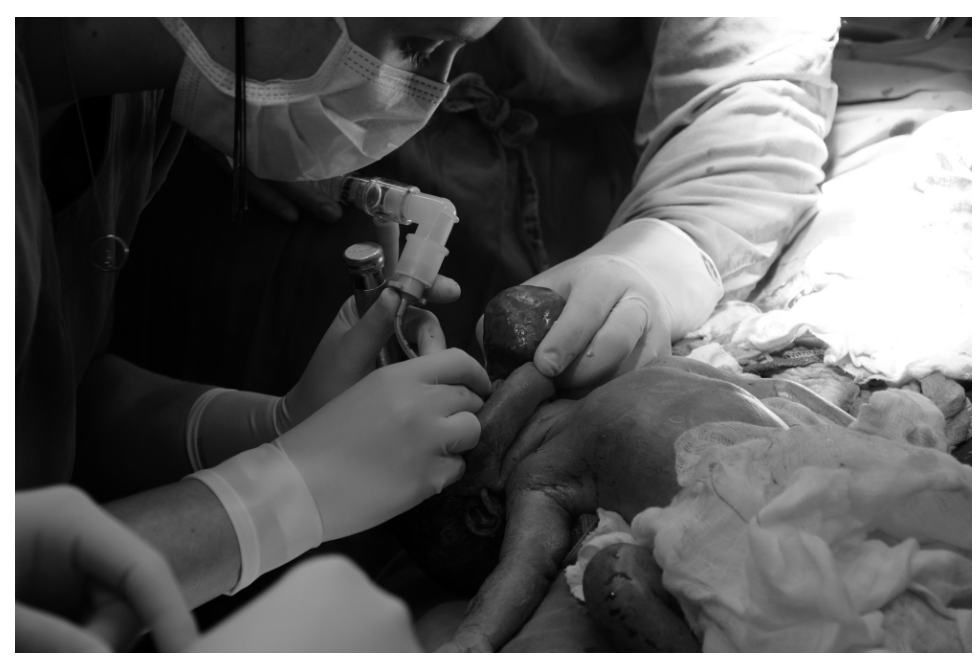

Figure 4 - Intubation. Note that the tumor is removed by a group member in order to enable laryngoscopy.

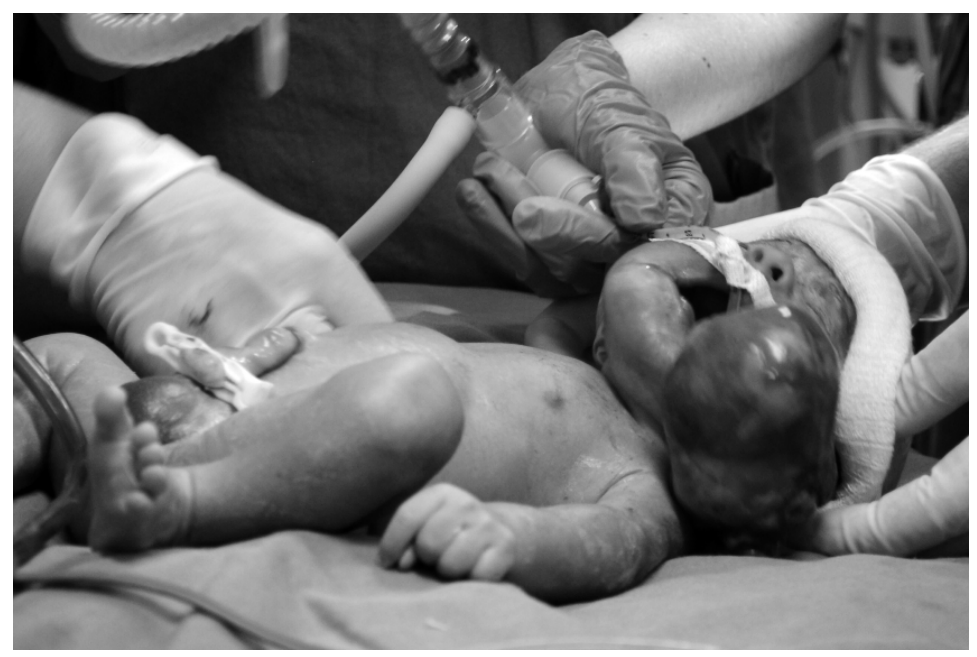

Figure 5 - Fetus with the Airways Secured and Ready for Neonatal Care. The great tumor in the oral region of the fetus did not impede intubation, as it is a pedicled tumor.

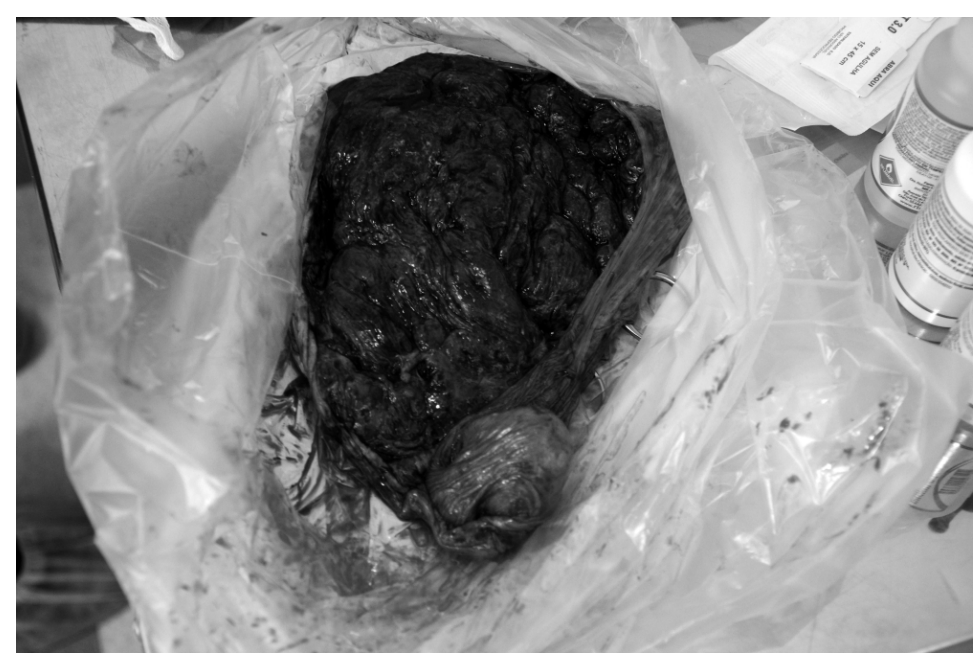

Figure 6 - Tumor Adhered to the Placenta can be Noticed on the Bottom of the Figure. 
patient was extubated at the end of the procedure without having to reverse the neuromuscular blockade. In Figure 6, it is possible to see the unusual occurrence of teratoma in a placenta.

The blood from the umbilical cord coagulated and, therefore, it was not possible to perform the blood gas analysis.

\section{DISCUSSION}

The cases of cervical or oral malformations causing airway obstruction are extremely complex. Therefore, in order to successfully perform the EXIT procedure, the participation of multidisciplinary groups, including the specialties of obstetrics, neonatology, anesthesia and head and neck surgery is fundamental ${ }^{1}$. The early evaluation of the parturient by these specialists makes it possible to plan the appropriate manner to deal with the case.

Since 1970, with the development of ultrasonography, the intrauterine diagnosis of congenital anomalies was made possible. In the last decade, it was possible to notice a rapid improvement of high-resolution imaging diagnosis, such as the ultrafast NMR and the ultrasonography itself 2,10 .

The EXIT procedure was successfully used in cases in which it is possible to anticipate the difficulties related to the access to the neonate's airways ${ }^{6,7,11,12}$. After uterine incision, only the fetal head is delivered. Uterine volume and fetoplacental circulation are maintained, securing oxygenation during access to the airways $6,12,13$. Once the airways of the fetus are secured, the umbilical cord may be clamped and delivery may be completed. After birth, halogenated concentration reduction and venous infusion of oxytocin reverse uterine relaxation.

The anesthesia for fetal surgery involves simultaneous treatment and monitoring of two patients, mother and fetus. Unlike the anesthesia for conventional cesarean, the transplacental passage of the anesthetics is necessary to provide fetal anesthesia and immobility ${ }^{7,14}$. In addition, physicians should maintain the uterus relaxed during the procedure. General anesthesia using halogenated agents is a technique recommended for fetal surgery performed outdoors and in cases of EXIT procedure ${ }^{8,14,15}$. Neuraxial anesthesia and intravenous injection of nitroglycerin for uterine relaxation are an alternative technique ${ }^{16}$. The main advantage of this technique is to avoid risks related to general anesthesia for pregnant women. However, in order to achieve an appropriate uterine relaxation, high doses of nitroglycerin, which cause hypotension and headache, may be necessary ${ }^{16}$. Uterine relaxation can also be obtained through intravenous injection of magnesium sulfate ${ }^{17}$.

Anesthesia is administered to the fetus through the placenta. This depends on the difference between the partial pressure of the anesthetic in the maternal and fetal blood, on the solubility of the anesthetic in the fetal blood and on the distribution of the anesthetic throughout the fetal circulation. Biehl et al. ${ }^{18}$ studied the use of $2 \%$ isoflurane in eight sheep. According to their remarks, the anesthetic crosses the placen- ta rapidly and appears in the fetal circulation two minutes after anesthesia. However, the balance between maternal and fetal concentration of isoflurane occurs slowly. After 90 minutes of anesthesia, the anesthetic concentration on the fetal blood was only two-thirds of the mother's concentration ${ }^{18}$. In a study carried out with 12 women undergoing cesarean section under general anesthesia with $0.8 \%$ isoflurane introduced in oxygen and nitrous oxide at $50 \%$, the authors ${ }^{19}$ noticed that after 60 minutes of anesthesia, the isoflurane concentration in the fetal blood was approximately $70 \%$ of the mother's concentration. The slow increase and the concentration difference of anesthetics in the fetal blood do not prevent from obtaining the appropriate anesthesia, as the minimum alveolar concentration (MAC) of the fetus is lower ${ }^{18}$. The use of high concentrations of isoflurane seems to play a more important role in maintaining the uterine relaxation than the fetal anesthesia itself. Besides, intramuscular fentanyl (10-20 $\left.\mu \mathrm{g} \cdot \mathrm{kg}^{-1}\right)$, ketamine $\left(5 \mu \mathrm{g} \cdot \mathrm{kg}^{-1}\right)$, vecuronium $\left(0.2 \mathrm{mg} \cdot \mathrm{kg}^{-1}\right)$ or rocuronium $\left(1 \mathrm{mg} \cdot \mathrm{kg}^{-1}\right)$ may be used adjunctively to the fetal anesthesia. In the cases mentioned, the fetuses did not react to the maneuvers involving laryngoscopy and tracheal intubation; therefore, it was not necessary to use opioids and neuromuscular blockers adjunctively to the fetal anesthesia, despite the short period of exposure to isoflurane. Fetal reaction to the maneuvers involving laryngoscopy and tracheal intubation should be avoided due to the risk of causing vigorous movements and breathing efforts that may cause physiological changes from the fetal circulation to the adult's circulation, reducing the placental flow ${ }^{21}$.

When the fetus changes to the adult-type circulation, he begins to depend on his own pulmonary ventilation and oxygenation, therefore, limiting the time to secure access to the airways ${ }^{14,22}$. In order to avoid fetal movements and breathing efforts, it is possible to administer opioids and muscle relaxants within a muscle ${ }^{7,14,22}$.

Fetal oxygenation depends on the uterine and umbilical cord blood flow. The arterial oxygen content in the mother's blood and the fetal hemoglobin concentration are other important aspects involved in the fetal oxygenation. The uterine blood flow can be appropriate if the uterus remains relaxed and if the mother's arterial pressure (AP) is maintained in a limit up to $10 \%$ of the initial AP ${ }^{2}$. The use of $2 \%$ isoflurane in $100 \%$ oxygen enables an appropriate uterine relaxation and maintains the mother's $\mathrm{pO}_{2}$ high. However, the prolonged use and high doses of halogenated anesthetics (higher than 2 MAC) can also lower the mother's blood pressure and the uterine placental flow ${ }^{23,24}$. Therefore, it is important to administer halogenated anesthetics in uterolytic doses, but without jeopardizing the mother's cardiovascular system. If the mother's AP lowers, it must be immediately corrected with vasoconstrictor agents (ephedrine and phenylephrine) ${ }^{17,22}$. On the other hand, the umbilical cord blood flow depends on the fetal circulation. It is important to maintain the fetus' cardiac output in order to assure placental perfusion and fetal oxygenation. Maternal arterial oxygen content may be increased together with ordinary $\mathrm{FiO}_{2}$ increase and erythrocyte concentrate transfusion, if necessary ${ }^{25}$. If possible, most of the fetal body should be main- 
tained inside the uterus during procedure, in order to minimize heat loss to the external environment and preserve the umbilical blood flow. The fetal blood volume is low; therefore, if blood loss is approximately $10 \mathrm{~mL}$, blood transfusion may be necessary ${ }^{2}$. The fetus should receive "O negative" blood in case of hemorrhage ${ }^{2}$. Fetal well being plays an important role in the early diagnose of impaired placental perfusion and can be monitored by different methods 4,2,26,27. Fetal heart rate can be monitored through the umbilical cord pulse, just as it was performed in our cases, or through echocardiography, which also gives information on end-systolic volume, contraction and the filling of the heart chambers ${ }^{27}$. Oxygenation may be assessed by using pulse oximetry (saturation should be higher than 50\%) and through the analysis of fetal blood gas. Fetal suffering is related to heart rate lower than $120 \mathrm{bpm}$, pulse oxymetry lower than $40 \%$ and acidosis ${ }^{14}$.

In a normal cesarean section, placental blood flow decreases during hysterotomy ${ }^{28}$. The time gap between hysterotomy and the nenonate's birth seems to be extremely important for fetal well being at the end of the EXIT procedure. In a case report involving three cesarean sections with EXIT procedure under general anesthesia with isoflurane administered in a concentration of $1.8 \%$ to $2.5 \%$, Gaiser et al. ${ }^{4}$ analyzed the umbilical cord gas values. In each case, total time from hysterotomy and delivery was 10, 12 and 29 minutes, and the umbilical cord arterial blood obtained at delivery was higher than $\mathrm{pH} 7.22$ in all cases ${ }^{4}$. In another case report of the use of anesthesia with isoflurane for cesarean delivery of a twin gestation with EXIT procedure performed in one of the fetus with a giant neck mass, the author documented fetal acidosis in both of the fetuses ${ }^{29}$. Total time from hysterotomy and delivery was 20 minutes for the normal fetus and 35 minutes for the one with a neck mass. After birth, the umbilical cord arterial blood was $\mathrm{pH} 7.07$ and 7.10 respectively. Despite the relatively short time gap between hysterotomy and delivery, there was prolonged exposure to isoflurane (58 minutes for the normal fetus and 72 minutes for the second) ${ }^{29}$. In addition, the fetuses were twins, which makes the procedure more difficult. The evolution of the normal neonate was favorable and he was extubated after 17 minutes without difficulties ${ }^{29}$. In a thorough clinical report of 45 cases, Cauldwell ${ }^{7}$ did not observe fetal acidosis, not even in a case in which the author maintained the uterus relaxed for two hours. In our cases, the time gap between hysterotomy and umbilical cord clamping was approximately 10 minutes, because clamping occurred only after the fixation of the orotracheal intubation, despite previous intubation. In the first case, the analysis of the umbilical cord's arterial blood between the first minute $(\mathrm{pH} 7.27)$ and the seventh minute $(\mathrm{pH} \mathrm{7.24)}$ of the EXIT procedure did not reveal fatal acidosis $(\mathrm{pH}<7.20$ is considered to be fetal acidosis). In the second case, the umbilical cord blood coagulated and it was not possible to perform gas analysis. During the procedures, fetal oxygenation was appropriate. According to the studies presented, total time from uterus incision and umbilical cord clamping should be limited to 60 minutes, but ideally time gap should be less than 30 minutes ${ }^{2,22}$.
Uterine relaxation may be achieved by administering different volatile agents, such as isoflurane and sevoflurane in concentrations of 2 MAC 2,15,30,31. Concentrations higher than 2 MAC of halogenated anesthetics are associated to the development of maternal arterial hypotension, uterine flow reduction, hypoxia and fetal acidosis ${ }^{32}$. In both cases, the uterine relaxation obtained with $2 \%$ isoflurane was satisfactory for the whole procedure, without maternal arterial hypotension. However, in order to obtain an appropriate uterine relaxation, it was not necessary to use tocolytic agents, such as magnesium sulfate and nitroglycerin ${ }^{4}$, despite the halogenated anesthetic. Nitroglycerin is the best agent to perform EXIT procedures due to its rapid and short term onset, enabling the return of the uterine tonus right after interruption ${ }^{29}$. It can be used in intermittent bolus of 50 to $100 \mu \mathrm{g}$ through venous access or in continuous infusion of 10 to $20 \mu \mathrm{g} \cdot \mathrm{kg}^{-1} \cdot \mathrm{min}^{-1} 22,33$. Despite being ideal for EXIT procedures, nitroglycerin can cause hypotension and must be readily corrected with vasoconstrictor agents to maintain uterine perfusion ${ }^{22,33}$. Magnesium sulfate can also be used in bolus of 2 to $3 \mathrm{~g}$ through venous access and maintenance of continuous infusion of $2 \mathrm{~g} \cdot \mathrm{h}^{-1}$ 29,34. Adverse effects associated to the use of manganese sulfate include respiratory and cardiovascular depressions, as well as a prolonged effect of neuromuscular blockers.

The preservation of the uterine volume during the EXIT procedure is fundamental for the maintenance of the placental flow, avoiding placental displacement and fetal asphyxia 22. With the airways secured, the fetus is totally delivered from the uterine cavity, the umbilical cord is clamped and the uterine relaxation is reversed.

The high doses of inhalational anesthetics must be discontinued after umbilical cord clamping to avoid uterine atony. Despite the use of oxytocin, physicians should reduce the concentration of volatile anesthetics to less than 0.5 MAC and add to the mother's anesthesia other anesthetic agents, such as opioids, nitrous oxide, or administer epidural anesthesia via a previously installed catheter ${ }^{17}$. Depending on the case, the neonate is sent to an appropriately prepared room or to a neonatal intensive care unit. In the cases presented in this study, uterine contraction was appropriate after having reduced the inspired concentration of isoflurane to $0.5 \%$ and used $15 \mathrm{IU}$ oxytocin in continuous infusion. Estimates of blood loss during the whole procedure were similar to the loss in conventional cesarean.

Reports describe the successful use of general balanced anesthesia using isoflurane as the main uterine relaxant to perform cesarean section followed by EXIT procedure in fetuses with tumors obstructing the airways. The procedures established in anesthesia for fetal surgery are based on studies involving animals and mainly on clinical experience reported through case studies. Fetal surgery is a medical field in rapid development. Anesthesiologists should follow this development and be prepared to treat patients appropriately and safely. 
HELFER, CLIVATTI, YAMASHITA E COL.

\section{REFERÊNCIAS/REFERENCES}

1. Tanaka M, Sato S, Naito $\mathrm{H}$ et al. - Anesthetic management of a neonate with prenatally diagnosed cervical tumor and upper airway-obstruction. Can J Anaesth, 1994;41:236-240. 
2. Myers LB, Cohen D, Galinkin J et al. - Anaesthesia for fetal surgery. Paediatr Anaesth, 2002;12:569-578.

3. De Backer A, Madern GC, van de Ven CP et al. - Strategy for management of newborns with cervical teratoma. J Perinat Med, 2004;32:500-508.

4. Gaiser RR, Cheek TG, Kurth CD - Anesthetic management of cesarean delivery complicated by ex utero intrapartum treatment of the fetus. Anesth Analg, 1997; 84:1150-1153.

5. Shih GH, Boyd GL, Vincent RD et al. - The EXIT procedure facilitates delivery of an infant with a pretracheal teratoma. Anesthesiology, 1998;89:1573-1575.

6. Schwartz DA, Moriarty KP, Tashjian DB et al. - Anesthetic management of the EXIT (ex utero intrapartum treatment) procedure. J Clin Anesth, 2001;13:387-391.

7. Cauldwell $C B-$ Anesthesia for fetal surgery. Anesthesiol Clin North America. 2002;20:211-226.

8. Gogarten W, Van Aken H, Marcus MA - Fetal surgery: general or regional anaesthesia? Curr Opin Anaesthesiol, 2000;13:277-281.

9. Cox PB, Gogarten W, Strumper D et al. - Fetal surgery, anaesthesiological considerations. Curr Opin Anaesthesiol, 2004;17:235-240.

10. Courtier J, Poder L, Wang ZJ et al. - Fetal tracheolaryngeal airway obstruction: prenatal evaluation by sonography and MRI. Pediatr Radiol, 2010;40:1800-1805.

11. Stevens GH, Schoot BC, Smets MJW et al. - The ex utero intrapartum treatment (EXIT) procedure in fetal neck masses: a case report and review of the literature. Eur J Obstet Gynecol Reprod Biol, 2002;100:246-250.

12. Botto HA, Boailchuk ID, Garcia C et al. - Ex utero intrapartum treatment - Management of neonatal congenital high airway obstruction syndrome. Case report. Arch Argent Pediatr, 2010;108:E92-E95.

13. Schwartz MZ, Silver H, Schulman S - Maintenance of the placental circulation to evaluate and treat an infant with massive head and neck hemangioma. J Pediatr, 1993;28:520-522.

14. Zadra N, Giusti $F$, Midrio $P$ - Ex utero intrapartum surgery (EXIT): indications and anaesthetic management. Best Pract Res Clin Anaesthesiol, 2004;18:259-271.

15. Dahlgren G, Tornberg DC, Pregner K et al. - Four cases of the ex utero intrapartum treatment (EXIT) procedure: anesthetic implications. Int J Obstet Anesth, 2004;13:178-182.

16. George RB, Melnick AH, Rose EC et al. - Case series: Combined spinal epidural anesthesia for Cesarean delivery and ex utero intrapartum treatment procedure. Can J Anaesth, 2007;54:218-222.

17. Braga A de F, Rousselet MS, Zambelli H et al. - Anestesia para correção intra-útero de mielomeningocele. Relato de caso Rev Bras Anestesiol, 2005;55:329-335.

18. Biehl DR, Yarnell R, Wade JG et al. - The uptake of isoflurane by the foetal lamb in utero: effect on regional blood flow. Can Anaesth Soc J, 1983;30:581-586.

19. Dwyer R, Fee JPH, Moore J - Uptake of halothane and isoflurane by mother and baby during cesarean-section. Br J Anaesth, 1995;74:379383.

20. Reynolds LM, Lau M, Brown R et al. - Intramuscular rocuronium in infants and children - Dose-ranging and tracheal intubating conditions. Anesthesiology, 1996;85:231-239.

21. Giannakoulopoulos X, Sepulveda W, Kourtis P et al. - Fetal plasmacortisol and beta-endorphin response to intrauterine needling. Lancet, 1994;344:77-81.

22. Braga A FA, Frias JAF, Braga FSS et al. - Anestesia para tratamento intraparto extra-útero em feto com diagnóstico pré-natal de higroma na região cervical. Rev Bras Anestesiol, 2006;58:278-286.

23. Tame JD, Abrams LM, Ding XY et al. - Level of postoperative analgesia is a critical factor in regulation of myometrial contractility after laparotomy in the pregnant baboon: Implications for human fetal surgery. Am J Obstet Gynecol, 1999;180:1196-1201.

24. Fauza DO, Berde CB, Fishman SJ - Prolonged local myometrial blockade prevents preterm labor after fetal surgery in a leporine model. J Pediatr Surg, 1999;34:540-542.

25. Ramanathan S, Gandhi S, Arismendy J et al. - Oxygen-transfer from mother to fetus during cesarean-section under epidural-anesthesia. Anesth Analg, 1982;61:576-581.
26. Eschertzhuber S, Keller C, Mitterschiffthaler G et al. - Verifying correct endotracheal intubation by measurement of end-tidal carbon dioxide during an ex utero intrapartum treatment procedure. Anesth Analg, 2005;101:658-660.

27. Abraham RJ, Sau A, Maxwell D - A review of the EXIT (ex utero intrapartum treatment) procedure. J Obstet Gynaecol, 2010;30:1-5.

28. Dick WF - Anesthesia for cesarean-section (epidural and general) - effects on the neonate. Eur J Obstet Gynecol Reprod Biol, 1995;59:S61-S67.

29. Gaiser RR, Kurth CD, Cohen D et al. - The cesarean delivery of a twin gestation under 2 minimum alveolar anesthetic concentration isoflurane: one normal and one with a large neck mass. Anesth Analg, 1999;88:584-586.

30. Bui TH, Grunewald C, Frenckner B et al. - Successful EXIT (ex utero intrapartum treatment) procedure in a fetus diagnosed prenatally with congenital high-airway obstruction syndrome due to laryngeal atresia. Eur J Pediatr Surg, 2000;10:328-333.

31. Turner RJ, Lambrost M, Holmes $C$ et al. - The effects of sevoflurane on isolated gravid human myometrium. Anaesth Intensive Care, 2002;30:591-596.

32. Palahniuk RJ, Schnider SM - Maternal and fetal cardiovascular and acid-base changes during halothane and isoflurane anesthesia in the pregnant ewe. Aneshtesiology, 1974;41:462-472.

33. Rosen MA, Andreae MH, Cameron AG - Nitroglycerin for fetal surgery: fetoscopy and Ex Utero intrapartum Treatment Procedure with Malignat Hypertermia Precautions. Anesth Anag, 2003;96:698-700.

34. Yamashita AM, Moron AF - Anestesia para cirurgia fetal, Em: Yamashita AM, Gozzani JL. Anestesia em Obstetrícia, 2ª ed, São Paulo, Editora Atheneu; 2007, pp. 347-355. 